\title{
O Instituto Evandro Chagas em busca da preservação patrimonial: estudos preliminares
}

Instituto Evandro Chagas in the pursuit of patrimonial preservation: preliminary studies

El Instituto Evandro Chagas en busca de la preservación patrimonial: estudios preliminares

Claudia Regina Ferreira Santos

Centro de Documentação, Informação e Memória, Instituto Evandro

Chagas/SVS/MS, Ananindeua, Pará, Brasil

Os lugares de memória nascem e vivem do sentimento que não há memória espontânea, que é preciso criar arquivos, que é preciso manter aniversários, organizar celebrações, pronunciar elogios fúnebres, notariar atas, porque essas operações não são naturais.

Pierre Nora

Casarão de estilo eclético, situado em Belém, Estado do Pará, Brasil, no bairro do Marco, na Avenida Almirante Barroso, ainda hoje chama a atenção dos transeuntes. Tal construção abrigou, ao longo de muito tempo, uma instituição que é bastante significativa em termos de saúde pública na Região Amazônica (Figura 1). O Instituto Evandro Chagas, denominado inicialmente Instituto de Pathologia Experimental do Norte (IPEN), lá se estabeleceu no momento de sua criação, em novembro de 1936, por ato do governador José Malcher'.

Sobre a instalação do IPEN, pode-se dizer que ela está diretamente ligada aos estudos desenvolvidos pelo então Instituto Oswaldo Cruz, onde se identificou a presença de casos de leishmaniose no interior do País, o que levou posteriormente à criação de uma comissão para a investigação dessa doença. Tal comissão foi chefiada pelo dr. Evandro Chagas, já médico com comprovada experiência clínica e de pesquisa que, chegando ao Pará, conseguiu apoio do governo estadual para o início de suas ações².

No relatório do ano de 1936, dirigido ao diretor do Instituto Oswaldo Cruz ${ }^{3}$, Evandro Chagas narra os passos iniciais em Belém que concretizariam a possibilidade de desenvolvimento das pesquisas, a partir de sua chegada em 24 de outubro, contatando políticos de diferentes bancadas, que poderiam auxiliar na empreitada, e acompanhando todos os momentos, desde a apresentação do projeto de lei na Assembleia Legislativa Estadual até sua efetiva aprovação. Nesse mesmo período estudava também o local apropriado para a instalação do serviço de pesquisas rurais no interior do Estado, que acabou por ser definido na cidade de Abaeté, a $53 \mathrm{~km}$ da capital.

\footnotetext{
Correspondência / Correspondence / Correspondencia:

Claudia Regina Ferreira Santos

Instituto Evandro Chagas/SVS/MS

Centro de Documentação, Informação e Memória

Rodovia BR 316 km 7, s/n. Bairro: Levilândia

CEP: 67030-000 Ananindeua-Pará-Brasil

Tel.: +55 (91) 3214-2183

E-mail: claudiasantos@iec.pa.gov.br
}

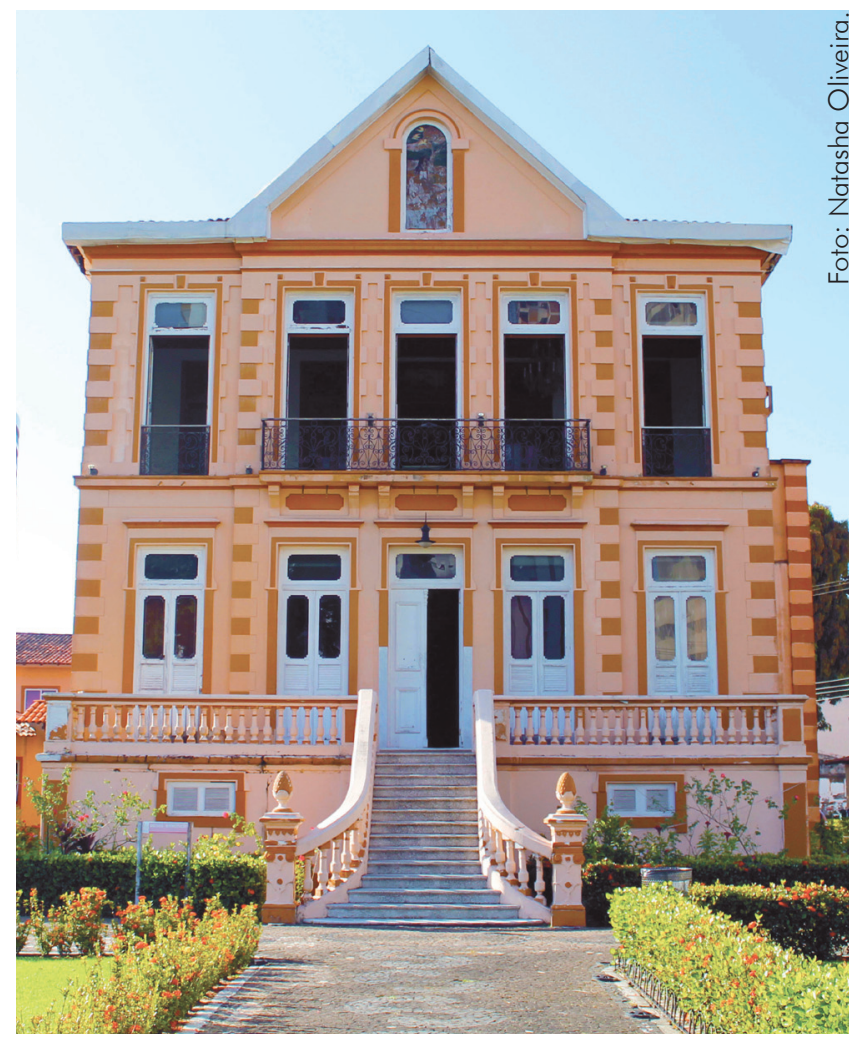

Figura 1 - Prédio que abrigará o Museu Evandro Chagas em Belém, Estado do Pará, Brasil

É interessante observar que na estrutura delineada para - IPEN, constante em seu regulamento de funcionamento publicado em 11 de novembro de 19364, está presente o serviço de museu. Percebe-se na existência desse serviço a influência da estrutura do Instituto Oswaldo Cruz, que desde sua fundação também contava com um museu em seu organograma. Esses espaços funcionavam como locais de pesquisa e de formação teórica e prática dos alunos, e suas coleções eram estratégicas para a construção do conhecimento científico.

Apesar do museu já existir no regulamento de 1936, somente em meados dos anos 2000, o assunto começou a ser trabalhado, quando boa parte da instituição já 
estava instalada no Município de Ananindeua*. Como afirma Nora $^{6}$ na epígrafe, não sendo espontâneos nem naturais, os lugares de memória, como os museus, devem ser planejados, pensados, arquitetados, com vistas à preservação da memória. Foi instituída, então, uma comissão interna para pensar em sua criação ${ }^{7}$. Fatores adversos fizeram com que o projeto, naquele momento, não seguisse adiante, apesar da profícua discussão inicial, assim como da coleta de algum material que posteriormente poderia ser incorporado ao acervo.

Com a nova e recente estruturação do Centro de Documentação, Informação e Memória - CEDIM, antiga Biblioteca, já se pode pensar efetivamente na questão, e executar ações de modo a concretizá-la. O CEDIM dispõe agora de profissionais de Museologia e História, e as equipes estão dedicadas aos procedimentos técnicos para a elaboração do projeto em termos de pesquisa patrimonial, institucional e dos objetos que farão parte da coleção.

E seguramente não haveria lugar mais emblemático para a instalação do Museu que o próprio casarão que abrigou a Instituição em seus primórdios, que testemunhou seu nascimento, importante exemplar de patrimônio arquitetônico de Belém. Nos levantamentos iniciais que estão sendo realizados em várias instituições, como bibliotecas e arquivos estaduais, municipais e federais, pôde-se averiguar que tal construção data do final do período áureo da borracha, época de Augusto Montenegro e de Antonio Lemos. $\bigcirc$ primeiro, governador do Estado do Pará de 1900 a 1908 e o segundo, à frente da Intendência Municipal de 1897 a 1912, são os responsáveis por imprimir a Belém mudanças na concepção urbana, dentro dos padrões europeus daquele momento e nos moldes do discurso civilizador, amparados, inequivocamente, pelos recursos provenientes da exportação gomífera ${ }^{8}$.

A Avenida Almirante Barroso, naquela época chamada Tito Franco, era parte do projeto de expansão do centro urbano para além do chamado Marco da Léguat, acompanhando a Estrada de Ferro de Bragança. Lá está situado um dos grandes monumentos do período, que é o Bosque Rodrigues Alves. Pois bem, a construção do casarão é atribuída ao engenheiro Henrique Santa Rosa ${ }^{10}$, aparentemente como uma residência particular, iá que a região constituía local onde se estabeleciam aqueles que buscavam tranquilidade e distância do movimento do centro urbano. $\bigcirc$ engenheiro, de família tradicional, foi por muitos anos diretor de Viação e Obras Públicas do governo estadual e dentre suas obras destacam-se relevantes construções da arquitetura paraense ${ }^{11}$. A suntuosidade de seu trabalho revela-se até os dias atuais.

Mas, há que se destacar também a produção intelectual de Santa Rosa, que é bastante significativa e extensa, tendo sido considerado importante geógrafo e historiador do período. Sobre Belém, afirma: "nossa capital é daquelas que reclamam mais ativos cuidados para a adaptação de suas condições telúricas e hidrológicas às da salubridade da população."12. Nesse sentido, mostra-se bastante afinado com as concepções modernizantes que se desenhavam para a nação naquele momento. $\bigcirc$ progresso, a modernidade e a civilização estavam na "ordem do dia", e Santa Rosa, como um representante do Estado, é um dos propagadores desse discurso.

Se o engenheiro construiu o casarão para si ou para outros, ainda não é possível dizer de forma decisiva. Sabe-se que vários proprietários existiram até que se estabelecesse o IPEN em 1936. De sua edificação, em 1908, fazendo parte daquele momento de desenvolvimento da cidade dentro da lógica do "processo civilizador", passando por abrigar uma instituição de saúde pública na década de 1930, até agora tornar-se um museu, pode-se começar a discussão referente à conquista da memória coletiva. Dentro da missão do Museu está presente a democratização da informação, possibilitando o acesso aos temas de saúde pública, de desenvolvimento da ciência e da tecnologia. Além disso, considera-se a valorização daqueles que ao longo do tempo participaram desse movimento, como atores ou como testemunhos. Nesse sentido, Le Goffli3 afirma:

\footnotetext{
A memória, na qual cresce a história, que por sua vez a alimenta, procura salvar o passado para servir ao presente e ao futuro. Devemos trabalhar de forma que a memória coletiva sirva para a libertação e não para a servidão dos homens.
}

Levando em conta a importância da memória coletiva, no que diz respeito à construção de identidades dentro de determinada comunidade, bem como para a elaboração das representações do passado, os profissionais envolvidos com o processo de elaboração do Museu estarão também trabalhando com ações que ampliem a participação da sociedade em suas atividades, seja por meio de exposições, cursos ou outros projetos, para que os grupos possam efetivamente entender-se e reconhecer-se como parte ativa do processo histórico.

Se no passado os museus eram entendidos como edifício, coleção e público, há novos significados agora para esses termos, que incluem as noções de território, patrimônio e comunidade ${ }^{14}$. Nesse sentido, ao lado de outras importantes instituições de saúde da Região Norte que já se dispuseram a contribuir para a preservação da memória institucional, como por exemplo, a Fundação Santa Casa de Misericórdia do Pará, o Museu Evandro Chagas tem também o intento de contribuir para a produção e difusão do conhecimento, especialmente em termos do patrimônio cultural da saúde. Memória da cidade, memória da saúde e memória coletiva manterse-ão protegidas e abrigadas nesses lugares de memória.

\section{AGRADECIMENTOS}

À equipe do Museu, Giselle Santos Silva, Clarissa Almeida Santos, Francisco Soares Chagas Neto, pela participação na pesquisa e coleta de fontes bem como na revisão do texto.

\footnotetext{
* A partir de 1940 o IPEN passou a chamar-se Instituto Evandro Chagas, em homenagem ao médico morto em acidente aéreo em novembro daquele ano 5 .

Primeira légua patrimonial doada à Câmara de Belém no século XVII. A medição, e consequente demarcação, no entanto, somente aconteceu no século XVIII?.
} 


\section{REFERÊNCIAS}

1 Pará. Lei Estadual n 59 de 10 de novembro de 1936. Crêa o Instituto de Pathologia Experimental do Norte e define suas attribuições. Belém: Officinas Graphicas do Instituto Lauro Sodré; 1936.

2 Guimarães MRC, Paula RN. Hospital de Manguinhos: 85 anos de pesquisa clínica. Rio de Janeiro: Fiocruz; 2004. p. 27-30.

3 Fundação Oswaldo Cruz. Casa de Oswaldo Cruz. Departamento de Arquivo e Documentação. Relatório de 25 de novembro de 1936 ao Diretor Geral do Instituto Oswaldo Cruz. Fundo Evandro Chagas: inventário. Rio de Janeiro; 2009.

4 Pará. Decreto n 2346 de 11 de novembro de 1936. Approva, para todos os effeitos legaes, o Regulamento annexo do Instituto de Pathologia Experimental do Norte. Belém: Officinas Graphicas do Instituto Lauro Sodré; 1936.

5 Deane LM. Histórico do Instituto Evandro Chagas: período 1936-1949. In: Instituto Evandro Chagas: 50 anos de contribuição às ciências biológicas e à medicina tropical. Belém: Fundação Serviços de Saúde Pública; 1986.

6 Nora P. Entre memória e história: a problemática dos lugares. Projeto História. 1993 dez;1 0:1 -178.
7 Ministério da Saúde (BR). Secretaria de Vigilância em Saúde. Portaria $n^{\circ} 75$ de 22 de novembro de 2004. Institui a Comissão de Implantação do Museu Evandro Chagas. Bol Serv. 2005 abr;20(16):57.

8 Derenji JS, Derenji J. Igrejas, palácios e palacetes de Belém. Brasília: Iphan; 2009. p. 101-4. (Roteiros do Patrimônio).

9 Cruz E. Ruas de Belém. 2. ed. Belém: Cejup; 1992.

10 Meira C. O Instituto Evandro Chagas. O Liberal 1991 maio 21 ;p.6.

11 Moraes TC. Geografia do poder: círculos intelectuais, natureza e historiografia na República Paraense século XX. In: Anais do 26 Simpósio Nacional de História 2011 jul; São Paulo: ANPUH.

12 Santa Rosa H. Visão Futura. In: Moura I, organizador. Annuário de Belém; p. 12-4.

13 Le Goff J. História e Memória. 5. ed. Campinas: Unicamp; 2003. p. 471.

14 Chagas M. Educação, museu e patrimônio: tensão, devoração e adjetivação. Rev Eletr Iphan [Internet]. 2006 jan-fev [citado 2013 jul 15];3. Disponível em: http://www.labjor.unicamp.br/patrimonio/materia. php?id=145. 